EVS25

Shenzhen China, Nov. 5-9, 2010

\title{
Strategic thoughts on the promotions of electric mobility
}

\author{
Yi CHEN ${ }^{1}$, Guangji JI ${ }^{1,2}$, Su ZHOU ${ }^{1,2,3}$ \\ ${ }^{1}$ School of Automotive Studies, Tongji University, Cao An Road 4800, Shanghai, 201804, China \\ ${ }^{2}$ Clean Energy Automotive Engineering Center, Tongji University, Cao An Road 4800, Shanghai, 201804, China \\ ${ }^{3}$ Sino-German Postgraduate School, Tongji University, Sipin Road 1239, Shanghai, 200092, China, Email: \\ suzhou@tongji.edu.cn
}

\begin{abstract}
Traditional mobility mostly relies on fossil fuels (e.g. the oil), but they will run out. Before the arrival of the depletion, we must get rid of our mobility dependence on the oil and prepare ourselves well for the advent of that day. Globally under urgent environmental protection mission and further tension between energy supply and demand, the transition of vehicular powertrains combined with the change or yet the revolution in mobility pattern is the trend of the times. Some thoughts and prospect are given here about the mobility pattern and its promotion. Similar to the Internet, a kind of Enternet (energy exchange network) could be constructed for the grid power to be shared and selected by energy users, in which distributed renewable power plants play a role as a "network terminal", and large-scale power plants (e.g. nuclear power plant, large-scale hydropower) as a "network server". It is here proposed to promote and introduce electric mobility in the near of renewable network terminals.
\end{abstract}

Keywords -Electric mobility, Transport pattern, Prospect, Enternet

\section{Introduction}

By a speech at Tsinghua University in July 2009, Mr. Steven Chu (Nobel Physics Prize winner) stated that, if everything goes the same as before, the hot days with the temperature higher than $32^{\circ} \mathrm{C}$ in Chicago would increase from current 10 days to 75-90 days per year in the future, heat waves in China would increase in frequency from every 20 years to every 2 to 3 year [1]. Since recent years, it has been warmly discussed that many changes have to be made now to maintain at least the present life style and life quality in the future. The similar opinions can also be heard from speeches of politicians, businessmen and academicians. Given that the transportation is a main contributor to energy consumption and gas emission and serves as an indispensable pillar in economy, such information is especially significant for automobile industry. With worldwide respect, the overall tendency of personal mobility realized by cars will continue and there will be more and more vehicles on the road. Therefore, automobile industry is exploring and developing innovative powertrains, being more economic, more environment-friendly and more sustainable than traditional powertrains.

\section{Urgent environmental protection}

\section{missions}

Thousands of years ago, the mankind "fought against the sky" - struggled against the nature to obtain living space and to improve living condition, it is the mankind-nature harmonious phase in the human history. But the situation changed then. During the past 250 years, incessantly taking advantage of the technologies (the steam engine, the mining of minerals and petroleum, and building dams, etc.), the mankind has imposed such a large and deep impact on the nature that nowadays the nature must be elaborately protected against the intervention of the mankind, in order to rehabilitate back to its healthy state. Excessive exploitation of underground minerals and structural changes in environmental conditions exhausted and destroyed the nature. The desertification, the air pollution and the drinking water shortage are the reaction of "rebound" and "self-defense" to the mankind intervention from the nature. The disharmony between mankind and nature will definitely deteriorate the living quality and threaten the fundamentals of mankind's survival.

Closely related with fossil fuel consumption is the emission of harmful substances. The application of three-way catalysts and oxidation catalysts reveals a remarkable technological potential for controlling 
automobile emissions, such as carbon monoxide (CO), oxynitrides (NOx) and hydrocarbons, etc. Such harmful substances from the industrial and automobile emissions pollute our living environment over national, regional and even global scales in many aspects.

The "greenhouse effect", which is very familiar to us, describes the earth atmosphere warming due to the mankind's acts. Though the carbon dioxide is the main culprit, the effect of the methane and oxynitride should not be underestimated. Many simulation results show that, if the carbon dioxide will be continuously accumulated in the atmosphere, the global average temperature will increase by several degrees [2]. A considerable evidence for that is the several weeks' extension of the summer 2006 in some regions in Europe and China. The climate change caused by the greenhouse effect could result in an unpredictable impact on human being, such as the desertification and the massive polar glacier melting which could finally cause a global sea level rise.

Another more globally focused issue is that oxynitride can destroy ozone layer. The thinner the ozone layer is, the more the holes appear, thus the stronger the radiation of ultra UV rays on the surface of the earth is [3]. The ultra UV rays can damage the genetic cells of the earth livings. The ozone layer over some regions in Australia has been badly damaged, where the skin cancer rate is much times higher than that in other regions.

The regional problems related with the harmful substances, such as oxynitride, sulfur dioxide, ammonia and nitrogen compounds, etc., include mainly the acidification of lands and forests, and the over-nitrification of the soil and water caused by fertilization. Oxynitrides and hydrocarbons can be radiated by the sun to build ozone molecules, which can then be harmful. The road traffic contributes about half of emissions of carbon monoxide, oxynitride and hydrocarbon in the world. But for human beings, the particularly urgent issue lies in the greenhouse effect caused by carbon dioxide. Although the current road traffic accounts for only $12 \%$ of carbon dioxide emissions, considering the strong growth trend of global mobility, it is quite possible for the carbon dioxide emissions to increase 1-2 times in the future century, if the current technologies are not improved.

\section{Further tension between energy supply and demand}

The development of human civilization has highly relied on the use of energy. The use of the fire marks a leap of the evolution of human beings. The first fuel available for human use is the wood, which could be found everywhere and is regenerative. In the first industrial revolution, i.e. the time between middle of 18th and beginning of 19th century, the coal, one of the fossil fuels, was largely consumed. The steam engine, that drove the agricultural machines for the first time, was powered by the coal too. Nearly one century later, in the second industrial revolution, petroleum began to be applied as fuel. With the invention of combustion engines and diesel motors, the petroleum as fuel stepped on to historical stage of human development. Since 20th century, the industrial and domestic energy demand keeps on growing, as a result, nuclear power and natural gas have become new members of main energy sources for human use.

The first oil crisis started in October 1973, when the members of the OPEC proclaimed an oil embargo in response to the U.S. decision to re-supply the Israeli military during the Yom Kippur war and for the first time the oil was applied to exert political influence on industrial countries. Through this crisis, the fact has been realized that fossil fuels can not be indefinitely exploited. The limited storage of fossil fuels and the growing energy demand constitute an increasingly sharp contradiction, which lies especially in the following three aspects:

- More and more energy is consumed by the western industrial countries. The products and their manufacturing processes are more and more complex, and the auto electrical components, e.g. lights, radios, televisions, GPS, various electronic sensors and controllers etc., are always increasing.

- The world population keeps going up. It is in 1804 that the world population for the first time arrived at 1 billion while at November 10th, 1999, the official population statistics was 6 billion.

- The industrialization of the developing countries is also one of the factors resulting in the growing energy demand. In Europe, the average annual consumption of energy per person is equivalent to 5 tons of charred coal, and in the US to 13 tons, while in the developing countries only to 1 ton. Given that there are still ca. 2 billion people who currently have not yet experienced the electricity, the industrialization of the related countries will definitely contribute to growth of global energy consumption.

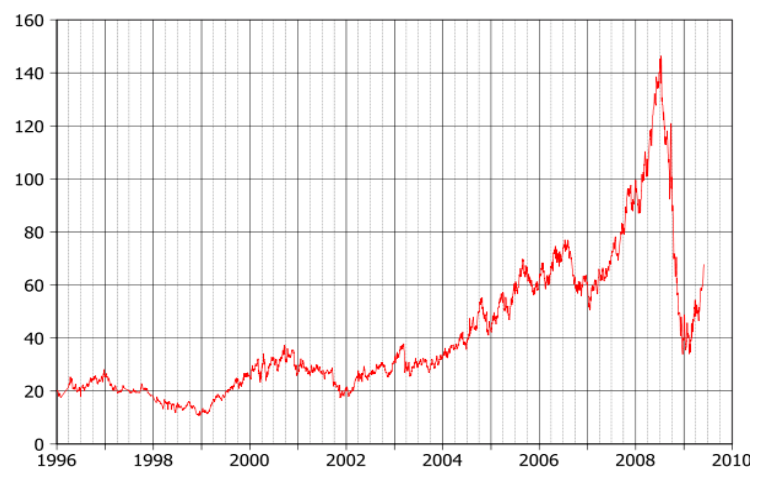

Figure 1: The oil price trend from 1996 to 2010(USD/Barrel)[4]

The consumption of fossil fuels including coal, oil and natural gas, i.e. the combustion of fossil fuels, 
accounts for more than $90 \%$ of the global energy consumption. According to experts, the transport-crucial oil would be only enough for one hundred years of use, if calculated by the current way and scale of consumption. This estimation may be too pessimistic. Conservatively assuming that the energy consumption grows at a rate of $1 \%$ per year, the oil's useful life will be reduced by 10 years. The IEA predicted that long-term energy shortages could be starting from 2010. The initial shortages may not lead to a particularly serious crisis. However, if the prediction comes true, the non-renewable energy, such as coal, oil, natural gas and uranium, may run out two hundred years later and the surge in energy prices at that time will be unimaginable. Fossil fuels (oil, coal and natural gas, etc.) as raw materials can be used to produce much more valuable chemical products, and it is a pure pity to mostly treat them as a fuel. Such types of raw materials which people consume immoderately today will become extremely scarce in the future. Eventually, the oil will run out. Before the arrival of the depletion of the oil, we must get rid of our dependence of energy on the oil and prepare ourselves well for the advent of that day.

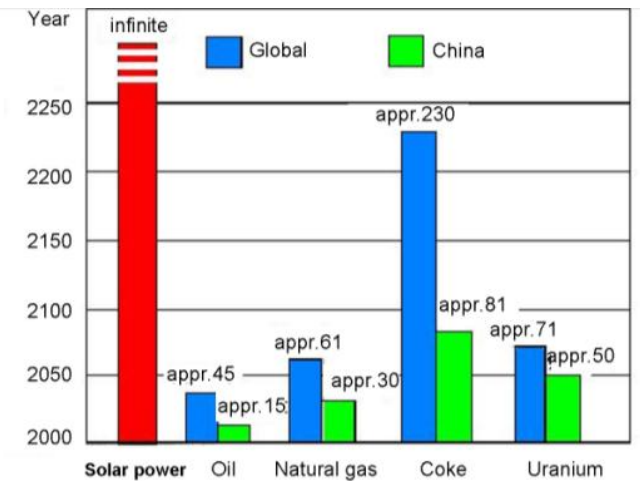

Figure 2: Energy reserves forecast map [5]

\section{The grid electricity at the epoch of fossil fuel scarcity}

Traditional power generation mostly relies on fossil fuels. No matter at present or in the future, electric vehicles with battery or fuel cell need electricity, as shown in Figure.3. It is natural to pose the question, where the gird electricity comes at the epoch of fossil fuel scarcity.

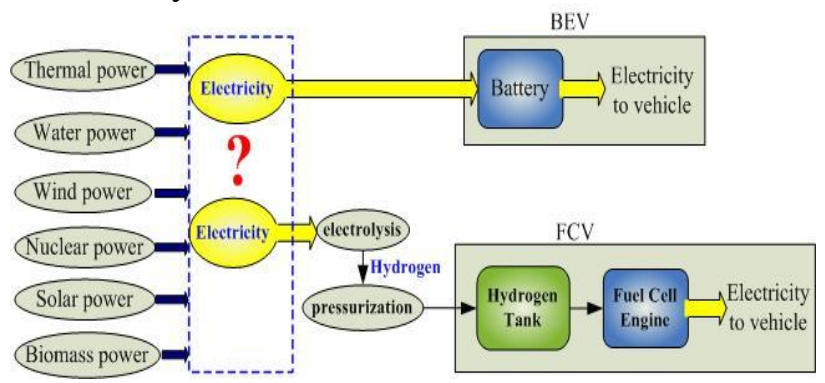

Figure 3: At the epoch of the fossil fuel scarcity, where does the electricity of the electric vehicles come from?
One idea is uranium, another raw material as energy carrier for large-scale power generation. In the world, about four hundred fission based nuclear power plants cover nearly $7 \%$ of the current energy demand. As well known, the uranium storage is also limited and can only be used for about hundred years. If nuclear power plants continue to generate electricity based on current principles of nuclear fission by using uranium and plutonium, the rest exploration time of uranium and plutonium is predictable. Theoretically speaking, this problem can be solved by the breeder reaction technology. Nevertheless, the technical problems have not yet been overcome, so this technology is far away from the practical application on power generation. Similar to the principle of the solar energy generation, tremendous energy can be obtained with the help of "thermonuclear fusion reaction of hydrogen isotopes", a prospective solution to the future energy problem in the eye of the scientists. However, the "nuclear fusion power "is still under the early research phase. If the commercialized nuclear fission plant is taken as an option to meet the global energy demand, then nearly ten thousand of such plants need to be built. Estimated according to this option, such a nuclear power plant must be put into operation every four days for one hundred years in the future, so that alternative energy is available in case of the depletion of the fossil fuels. Obviously, it is hardly realistic.

It is historically inevitable that electric vehicles will replace internal combustion vehicles in the long term for the human mobility. In the early phase of electric vehicles, only if the proportion of renewable energies in the electricity grid is gradually enhanced, the energy shortages and emission pollution can be fundamentally resolved. Great hope has been attached to the renewable energies, that is, the energies from the water power, wind power, solar power and terrestrial heat. However, the cost for the renewable energy technology is rather high, and could not be cut down in a foreseeable time. Moreover, due to present living and producing patterns, even if all renewable energy sources are optimally used, the future energy demand can yet not be met fully [6]. Right now the effective solutions to defer the depletion of the fossil fuels may be, 1)to introduce and then maintain strict energy-saving norms and standards, 2)to promote the popular energy-saving awareness and 3)to improve the energy-consuming processes from the exploitation to the end-user (e.g. from well to wheel) and to enhance the total energy efficiency. Similar to the Internet, a kind of Enternet [7] (energy exchange network) could be constructed for the grid power to be shared and selected by energy users, in which distributed renewable power plants (e.g. wind power plant, solar power plant) play a role as a "network terminal", and large-scale power plants (e.g. nuclear power plant, large-scale hydropower) as a "network server". Compared with the big cities far from renewable power plants, the regions near around these "network 
terminals" process the following main advantages for promoting electrical vehicles. At first, the zero-emission can be realized in the sense of well to wheel; secondly, electricity transport loss can be reduced significantly and thus the electrical mobility is more economic in the sense of well to wheel; finally, reasonable matching of the "network terminal" capacity with the beginning producing capacity of electric vehicles, offers an alternative pattern for promoting electric vehicles in the first phase. Taking the hydropower station for example, if electric mobility can be implemented near around, not only the hydropower station efficiency will be improved, but also the experimental and demonstrative roles will be played. On the one hand, this pattern can promote the environment-friendly transport and tourist industry in the relatively underdeveloped regions; on the other hand, the experiences gained can be continuously improved, and step by step be shared by other regions. To review the patterns of the industrial countries' living, production and mobility, which have long been regarded as a "model", is a profound-level social practice and has to be carried out to solve the future energy problems. With the revolutionary significance, this practice is very difficult, but may find a feasible solution.

\section{Thoughts about the mobility pattern}

Based on the combustion engines, the existing mobility pattern, including fuels, traffic roads and auxiliaries etc., is naturally favorable for combustion engine vehicles. The electric vehicles, as a new means of transport, are undoubtedly in an unfavorable position. The future development of electric vehicles depends largely on the change, even on the revolution in the mobility pattern. In fact, the electric vehicles development and the mobility pattern change mutually promote each other [8-9]. Currently, the number of the cars in the whole world is about 800 million, which increases at the rate of 30 million per year and will reach one billion by 2010. According to the U.S. Energy Department's long-term estimates, in 2050 global vehicle population will grow to 3.5 billion, of which that of the developed countries increased by about double, while that of the developing countries 15 times [10-12]. Under the traditional mobility pattern, on the one hand, the global oil supply will be unsustainable; on the other hand, the development of innovative vehicles [13-16], e.g. electric vehicle, will be even difficult. Hence, the transition of vehicular powertrains combined with the change or yet the revolution in mobility pattern is the trend of the times.

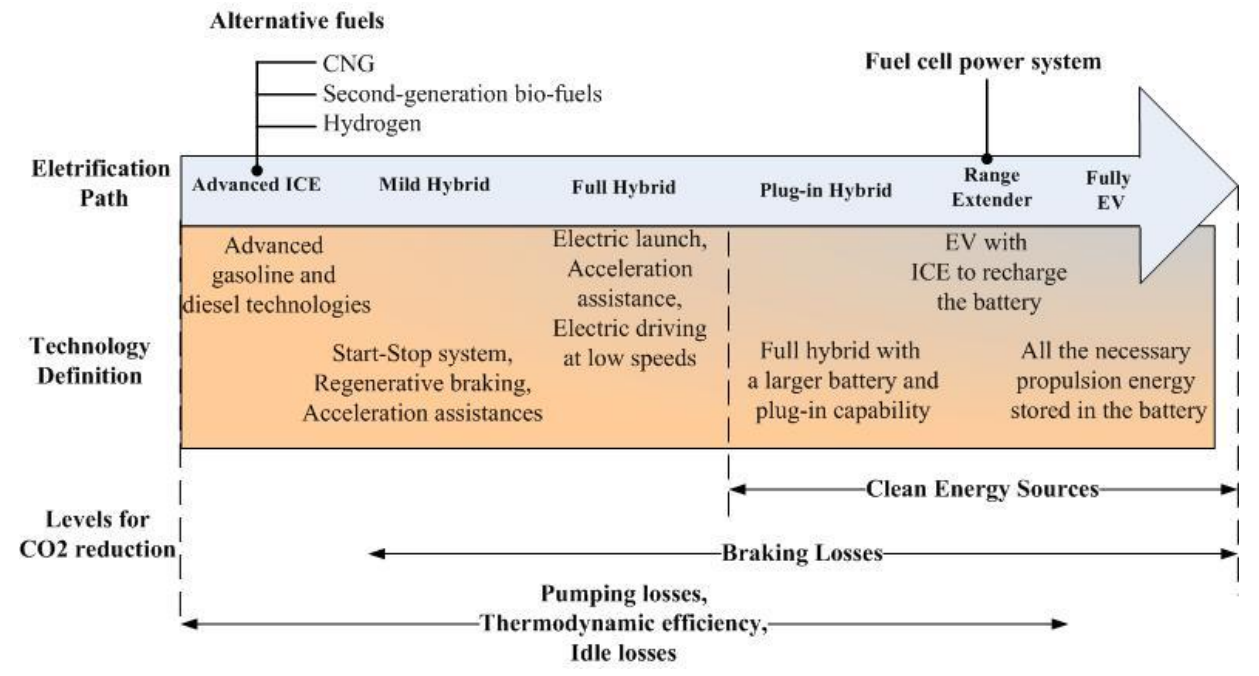

Figure 4: Prospects for the development of the automobile from the Boston Consulting [20]

Future urban and rural planning also needs some changes to promote and adapt the development of electric vehicles. Because of its fixed rails, punctuality and large capacity, the electric rail transport (e.g. light rail and metro) should be the first choice for the future urban transport mode. When urban and rural planning is carried out, the large residential areas, working areas, shopping and entertainment districts can be designed to be connected by rails. Rental points of "electric transporters", e.g. electric cars and electric bicycles, could be positioned at each rail station, to satisfy the personal demand on mobility within the region near around the station.

"Car-sharing" [17] is another new transport mode suitable for promoting electric cars. A group people can share the cars provided by a company, instead of emptying out their wallets to purchase and maintain an electric car. The electric cars will be fully charged ready for a certain $\mathrm{km}$ range, and can be rented at certain parking with no charging time. If the trip is quite distant, another fully charged electric car can be taken at a rental station on the way to move on. In the early developing phase of electric cars, it is inevitable to face some dissatisfaction, like high costs or infrastructure shortage or short driving range, and this "car-sharing" may degrade the dissatisfaction at certain extent. 


\section{Prospect of electric mobility}

It can be predicted that the combustion engine cars will still dominate in the future 50 years. Despite some new technologies, e.g. catalytic converter of gasoline vehicles, black powder filter of diesel vehicles etc., can effectively reduce the emissions of the harmful substances, the pollution from the combustion engine cars should not be underestimated because of rapid vehicle population rise. Besides, the use cost of the combustion engine cars will grow as the emission standard becomes stricter and the oil price ascends [18-19]. As a trend, the intervention of electric cars is as sure as nails.

In the "future automobile development road map" published by the Boston Consulting, the fully electric vehicle is considered as the ultimate goal for the mobility development, while the fuel cell vehicle is merely a tool as range extender for a certain period. However, we all know that at the current stage these two types of electric vehicles are being parallel developed. In light of the automobile history, if suitable electrode materials can be earlier found out to largely enhance the battery energy density and the fully electric vehicle finally gets rid of its short driving range, then the above mentioned prediction may be true [21-24]. Contrarily, if the hydrogen extraction, transport and storage can be earlier resolved and the fuel cell cut down as well as a sustainable no-platinum catalyst for fuel cells can be found out, then why the ultimate goal could not be the fuel cell vehicle?

\section{Conclusion}

The electric mobility is the trend of the next generation transportation. The source of the electricity is essential for both battery and fuel cell vehicles. An electric car can only be described as clean, if the source of the electricity is clean. In the early application phase of electric mobility, the corresponding promotion should be carried out in the near of renewable power sources, such as hydropower plant. The transition of vehicular powertrains will be combined with the change or yet the revolution in mobility pattern. In the future urban and rural planning innovative mobility pattern must be taken into account to promote electric vehicles.

\section{Acknowledgements}

This work is supported by the Chinese 111 Project (B08019) and AVL "Innovative Vehicle Powertrain" Professorship in CDHK/Tongji University, China.

\section{References}

[1]http://www.energy.gov/news2009/documents2009/Tsin ghua_Slideshow_final_for_distribution.pdf

[2]Chunshan Song, Global Challenges and Strategies for Control, Conversion and Utilization of CO2 for Sustainable Development involving Energy, Catelysis, Adsorption and
Chemical Processing, Catelysis Today, 115(1-4), 2006, pp: 2-32

[3]Michael Tausz, et al., Defense and Avoidance of Ozone under Global Change, Environmental Pollution, 147(3), 2007, pp: 525-531

[4]http://en.wikipedia.org/wiki/File:WTI_price_96_09.svg

[5]http://www.lrn.cn/stratage/resposition/200902/t20090201_32 3149.htm

[6]Yaxin Su, Introduction of Clean Energy and Renewable Energy, Chemical Industry Press, 2006, Beijing

[7]Su Zhou, Remarks on The Development of CPH (combined power and heat) Systems (Chinese), Journal of Chongqing University, vol.11 (2005), pp: 139-141

[8] B. van Bree, G.P.J. Verbong, G.J. Kramer, A Multi-level Perspective on The Introduction of Hydrogen and Battery-electric Vehicles, Technological Forecasting \& Social Change, 77, 2010, pp: 529-540

[9]Taiwen Feng, Liyan Sun, Ying Zhang, The Relationship between Energy Consumption Structure, Economic Structure and Energy Intensity in China, Energy Policy, 37(12), 2009, pp: $5475-5483$

[10]http://news.xinhuanet.com/auto/2005-03/23/content_27321 15.htm

[11]John M. German, Hybrid Electric Vehicles, Encyclopeida of Energy, 3, pp: 197-205

[12]Donald Karner, James Francfort, Hybrid and plug-in hybrid electric vehicle performance testing by the US Department of Energy Advanced Vehicle Testing Activity, Journal of Power Sources, 174, 2007, pp: 69-75

[13]Fredrik Carlsson, Olof Johansson-Stenman, Costs and Benefits of Electric Vehicles: A 2010 Perspective, Journal of Transport Economics and Policy, 37(1), 2003, pp: 1-28

[14]J.Chanaron, J.Teske, Hybrid Vehicles: A Temporary Step, International Journal of Automotive Technology and Management, 07, 2007, pp: 268-288

[15]Michi Nishihara, Hybrid or Electric Vehicles? A Real Options Perspective, Operations Research Letters, 38, 2010, pp: $87-93$

[16]Eckhard Karden, et al, Energy Storage Devices for Future Hybrid Electric Vehicle, Journal of Power Sources, 168, 2007, pp: 2-11

[17]http://en.wikipedia.org/wiki/Carsharing

[18]Alex M.K.P. Taylor, Science Review of Internal combustion Engine, Energy Policy, 36, 2008, pp: 4657-4667

[19]Maria Antonietta Costagliola, et al., Does European Type Approval Procedure Encourage the Diffusion of Hybrid and Other Low Emission Vehicles, SAE paper: 2010-01-1445, International Powertrains, Fuels and Lubricants Meeting, 2010

[20]The Boston Consulting Group, The Comeback of the Electric Car? Report, 2009, pp: 2

[21]M. Rosa Palacin, Recent Advances in Rechargeable Battery Materials: a chemist's perspective, Chemical Society Reviews, 38, 2009, pp: 2565-2575 
[22]T. Horiba, K. Hironaka, et al, Manganese-based Lithium Batteries for Hybrid Electric Vehicle Applications, Journal of Power Sources, 119-121, 2003, pp: 893-896

[23]W. McDowall, M. Eames, Forecasts, Visions, Backcasts, and Roadmaps to The Hydrogen Economy: a review of the hydrogen futures literature, Energy Policy, 34 (11), 2006, pp: $1236-1250$

[24]Su Zhou, Guangji Ji, et al, The State of The Art of PEMFC for Automotive Application, Chinese Automotive Engineering, 31(6), 2009, pp: 489-495

\section{Authors}

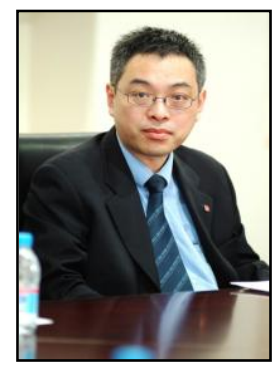

Yi Chen, born in 1963, received his bachelor's in 1986 in mechanical engineering and his master degree in thermal energy engineering (TEE) in 1992 at Tongji University in China. From 1992 to 1994 , he worked as a teaching assistant, lecturer, vice-director of the department of TEE and director of the laboratory. He has also worked as scientific researcher in the institute of internal combustion engine at TUBS (Technische Universität Braunschweig), in the research department of V W (Volkswagen) GmbH in Wolfsburg and in the department of law in Mannheim University, in Germany, respectively. Now, he is an associate professor in the college of automotive studies at Tongji University in China. His research interests mainly include clean automotive engineering and related promotion strategies.

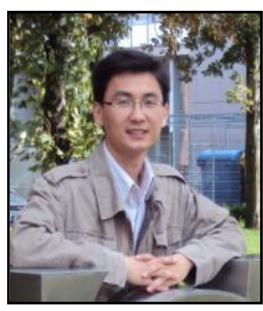

Guangji JI, born in 1981, received his bachelor degree in 2004 and Master degree in 2007 in vehicle application engineering in Nanjing Forestry University. He started his $\mathrm{PhD}$ project in Tongji since 2008. During 2009-2011, he visited Max-Planck-Institute/Magdeburg for continuing the $\mathrm{PhD}$ project on the fuel cell modeling and control directions. His research interests fall into the area of automotive electronics and clean energy powertrain modeling and control.

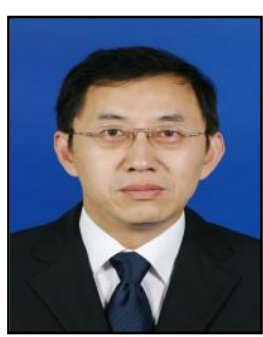

Su Zhou, born in 1961, received his master's in 1986 in China and his $\mathrm{PhD}$ degree in 1993 in Germany. He was a full professor of automation at Qingdao University in China since 1995 . He worked as $\mathrm{C} 1$ faculty of process engineering at Magdeburg University from 1999 to 2001, senior engineer in department of Control \& Simulation in the XcellS GmbH from 2001 to 2004, and senior engineer \& project manager in Webasto $\mathrm{GmbH}$ from 2004 to 2006, in Germany. Since 2006, he is a full professor in college of automotive studies and AVL chair professor in CDHK at Tongji University/China. His research interests mainly include modeling, simulation and control of innovative power trains. 